\title{
Consumer health organisations for chronic conditions: why do some people access them and others don't?
}

\author{
Adem Sav ${ }^{1}$, Sara S. McMillan ${ }^{2}$, Fiona Kelly ${ }^{3}$, Jennifer A. Whitty ${ }^{4}$, Elizabeth Kendall ${ }^{5}$, Michelle A. King ${ }^{6}$ and \\ Amanda J. Wheeler ${ }^{7}$ \\ ${ }^{1}$ Senior Research Assistant (PhD), Population and Social Health Research Program, Griffith Health Institute, Griffith \\ University, Meadowbrook, QLD, Australia \\ ${ }^{2}$ PhD Candidate, Population and Social Health Research Program, Griffith Health Institute, Griffith University, \\ Meadowbrook, QLD, Australia \\ ${ }^{3}$ Adjunct Research Fellow (PhD), School of Human Services and Social Work, Griffith Health Institute, Griffith \\ University, Meadowbrook, QLD, Australia \\ ${ }^{4}$ Senior Lecturer (PhD), Centre for Applied Health Economics, Griffith Health Institute, Griffith University, Australia \\ ${ }^{5}$ Professor, Director of Research (PhD), Population and Social Health Research Program, Griffith Health Institute, \\ Griffith University, Meadowbrook, QLD, Australia \\ ${ }^{6}$ Senior Lecturer (PhD), School of Pharmacy, Griffith Health Institute, Griffith University, Gold Coast, QLD, Australia \\ ${ }^{7}$ Professor (PhD), Population and Social Health Research Program, Griffith Health Institute, Meadowbrook, QLD, Griffith \\ University, Australia
}

\begin{abstract}
Background: Consumer health organisations (CHOs), which operate outside the mainstream healthcare system with a specific focus on supporting people to self-manage their health conditions, have become widespread. Yet, there has been little systematic research into $\mathrm{CHOs}$, including their perceived benefits and barriers, which encourage or deter their access by people with a variety of chronic health conditions. Aim: This study explored the benefits of $\mathrm{CHO}$ in self-management and also the barriers that inhibit their access, from the perspective of people with chronic conditions and their unpaid carers. Methods: In-depth, semi-structured interviews were completed with 97 participants across four regions of Australia. The sample included a high representation of people from culturally and linguistically diverse backgrounds and Aboriginal and Torres Strait Islander people as well as non-indigenous Australians. Findings: Three inter-related themes were identified that represented the benefits of involvement and participation in CHOs: knowledge and information, connection and support and experiential learning. However, limited access pathways emerged as a barrier that inhibited a person's entry into $\mathrm{CHO}$. Furthermore, the person's beliefs and experiences about their own health condition(s) also inhibited their continued participation in $\mathrm{CHO}$ programmes. Conclusion: Although our findings confirm that $\mathrm{CHO}$ s are a valuable resource in alleviating the 'work of being a patient' for some people, there seems to be some barriers that prevent their full access and utilisation. Structured integration systems to increase the reliable delivery and accessibility of $\mathrm{CHOs}$ are needed to ensure that people who would benefit from accessing them can do so.
\end{abstract}

Key words: benefits and barriers; chronic illness; consumer health organisation; self-management

Received 10 March 2013; revised 14 August 2013; accepted 5 January 2014

Correspondence to: Adem Sav, Population and Social Health Research Program, Griffith Health Institute, Room 2.16, Building L08, Griffith University, University Drive, Meadowbrook 4131, Australia. Email: a.sav@griffith.edu.au

\section{Introduction}

Chronic health conditions, such as diabetes and cardiovascular disease, have become a worldwide 
concern, representing almost $63 \%$ of all deaths globally (World Health Organization, 2011). With their increasing prevalence, 'self-management' has become a common concept in primary healthcare, being welcomed as a solution to the management of such conditions (Lorig and Holman, 2003). Various benefits to individuals and healthcare systems have been identified when people can effectively self-manage, by becoming more informed, involved and empowered in their own care (Blenkinsopp et al., 2009; Boyle et al., 2009). With an increasing emphasis on self-management, various healthcare initiatives such as 'Living Well' workshops and the Australian Better Health Initiative have been implemented, to provide people with the necessary skills, support and information to effectively self-manage (Boyle et al., 2011). In addition to formal healthcare services (eg, primary care services), informal organisations that generally operate outside the mainstream healthcare system with a specific focus on supporting people (including to self-manage their conditions), known as consumer health organisations (CHOs), have become widespread.

$\mathrm{CHOs}$ are broadly defined as 'organisations that promote and represent the interests of users or carers' (Allsop et al., 2004: 739). Many CHOs exist worldwide, although they vary considerably in their size, financial budgets, focus and activities (Boyle et al., 2007). They can range from a smallscale support group formed by several members who share a common health condition, to national organisations with formal governance structures and larger financial budgets. Coppa and Boyle (2003) outlined that some organisations can be funded or subsidised by governments or health services, while others can be small voluntary groups, relying exclusively on community support. Some CHOs can also receive funding from commercial organisations such as pharmaceutical and medical supply companies. CHOs can also be distinguished between those which are condition based, focusing on a specific chronic condition(s) (eg, Diabetes Australia, Arthritis Care United Kingdom, Anxiety Alliance, National Schizophrenia Fellowship), and those that are population based, which focus on a wide range of issues for specific groups, such as carers or cultural minorities (eg, Children's Health Foundation, Muslim Youth Helpline, National Careline; Allsop et al., 2004).
CHOs are largely based on the self-help movement of the 1970s, which led to the proliferation of self-help groups: small voluntary group structures formed by people who came together to satisfy a common need (Katz and Bender, 1976). With time, some self-help groups evolved into CHOs, becoming more 'professionalised', larger national entities, with formal governance structures. Many $\mathrm{CHOs}$ are now involved in ground-breaking scientific research, media campaigns, parliamentary lobbying, protests against adverse events, and have close links with local, state and national governments (Allsop et al., 2004; Jones et al., 2004). Some continue to maintain self-help roles within them and share a number of core functions including: empowerment and advocacy, the provision of educational resources, skills training and psychological support; services that may not be adequately offered by the formal healthcare system (Coppa and Boyle, 2003). CHOs can also provide practical, psychological and informational support to consumers and carers/family members in a variety of ways, including newsletters, counselling, alternative therapy, information sessions and workshops, websites and peer support groups (Young et al., 2010). There is some evidence that participation in such groups makes a significant contribution to user outcomes, including psychosocial well-being, expertise, health literacy and effective coping strategies (Kyrouz et al., 2002; Coppa and Boyle, 2003; Nijsten et al., 2005; Oliffe et al., 2011).

Despite their potential benefits, there has been little systematic research into $\mathrm{CHOs.} \mathrm{Few} \mathrm{studies}$ have focused on the perceived benefits of CHOs from the perspectives of consumers with a variety of ongoing health conditions (eg, Kyrouz et al., 2002; Coppa and Boyle, 2003; Boyle et al., 2009; Hoffmann and O'shea, 2012). Furthermore, of the studies that have been conducted, many focused on small voluntary type groups, rather than larger national groups, such as the American Lung Association or the Heart Foundation of Australia (eg, Coppa and Boyle, 2003). Most of what we know is based on homogenous samples, with little emphasis on the experiences of those from culturally and linguistically diverse (CALD), or Aboriginal and Torres Strait Islander people. In addition, there is an absence of research on how unpaid carers, those who provide assistance with a number of daily activities without pay to people 
with chronic conditions (Mcnamara and Rosenwax, 2010), access and utilise such organisations to meet their needs as carers.

Commensurate to the narrow understanding of the benefits of CHOs, there is limited research on the barriers that deter people from accessing such organisations (Coppa and Boyle, 2003). Most of the limited research has focused on articulating the barriers that appear to prevent primary healthcare professionals, mainly general practitioners (GPs), from referring patients to CHOs (Young et al., 2010; Boyle et al., 2011). Underdeveloped referral pathways, the perceived credibility of the information such organisations offer to consumers, and a limited awareness of CHOs among primary healthcare professionals and their role in self-management have been outlined as potential barriers (Laudet, 2000; Salzer et al., 2001; Young et al., 2010). Indeed, research suggests that despite the potential benefits of CHOs, only a small number of people (around 5\%) access them (Ellins and Coulter, 2005). However, the barriers that limit a person's involvement and participation in such organisations from a consumer perspective have not been clearly investigated. Much remains to be understood of the personal lived experiences of consumers themselves. Given the potential of CHOs to provide much needed support to people living with chronic conditions, understanding the barriers is important to increase access to, and maximise participation in such organisations.

The research questions addressed in this study were: (a) What are the benefits of CHOs in self-management from the perspective of people with chronic conditions and their unpaid carers? (b) What are the potential entry level barriers that limit a person's access to such organisations? (c) What are the potential progress level barriers, which inhibit the continued involvement of people in a CHO once they obtain entry? Our focus was on large national groups with formal governance structures and also small voluntary self-help groups. The study contributes to research by providing a comprehensive exploratory understanding of $\mathrm{CHO}$ experience from a large qualitative study of adults that included consumers and their carers, as well as representation from CALD backgrounds and Aboriginal and Torres Strait Islander people.

\section{Methods}

\section{Sampling and data collection}

The study was guided by the interpretive social paradigm (Neuman, 2010) and used qualitative research methods in accordance with its exploratory nature. Given the focus on obtaining an in-depth understanding and the limited research on this topic, an interpretive approach was considered the most appropriate method.

To take part in the study, participants needed to be (a) either newly diagnosed or have a chronic condition(s) for a minimum of six months, or (b) be an unpaid carer for a person with a chronic condition, or (c) be both (eg, an unpaid carer with a chronic condition). Participants were geographically located across four regions: LoganBeaudesert, and Mount Isa/North West regions of Queensland, Northern Rivers area of NSW and the greater Perth area of Western Australia. These regions represent diversity in geographical location, culture and socio-economic status in Australia. Because of the inclusive nature of the study, participants were included if they selfreported as having a chronic condition themselves, or were caring for someone that did. To account for potential differences in experiences, we included those who had recently begun to experience a chronic condition, as well as those having lived with such conditions for lengthy periods of time. People could not participate in the study if they were under 16 years of age, did not reside in one of the four data collection sites, did not experience a chronic condition or did not care for someone that did. Having prior contact with, or being a member of a $\mathrm{CHO}$ was not part of the inclusion criteria for this study. Instead, the focus was on chronic illness in general, with the aim of trying to elucidate how participants utilised support networks, including CHOs, to better manage their conditions. However, most of the participants elucidated that they had some form of contact with a $\mathrm{CHO}$.

Purposive and snowball sampling techniques were conducted to locate participants. Recruitment was largely conducted via the assistance of a large number of health organisations, such as community pharmacies, general practices, various healthcare agencies, and other government and non-government organisations. These organisations were asked to promote the study in their 
workshops, newsletters and meetings by distributing information sheets to their clients and/or networks. Recruitment was also conducted via the assistance of the study's Reference Group, which consisted of a culturally diverse group of key stakeholders with healthcare expertise. A short eligibility process was conducted with each participant who expressed interest in the study, to obtain information about their background demographics, health, condition(s) status and duration, and healthcare system utilisation. Those who participated in the interviews were asked to suggest other people they knew personally who would also be willing to participate.

An interview guide was developed, which was informed by previous stakeholder research on a similar topic (McMillan et al., 2012; Sav et al., 2012). The interview guide was piloted with several people with chronic conditions and comments were obtained from the Reference Group. In accordance with the overarching aim of the study, a consumer researcher was appointed to ensure that data collection and analysis maintained a consumer centred focus. Probe questions (Table 1) in the interview guide involved the extent and duration of health condition(s), self-management practices, coping strategies, support networks, involvement and participation in $\mathrm{CHO}$ programmes. Ethical approval for the study was obtained from a University Human Research Ethics Committee (PHM/12/11/HREC).

Semi-structured, in-depth interviews were conducted personally by members of the research team during May to October 2012. The interviews were conducted either face-to-face $(n=49)$ or via telephone $(n=48)$. The interviewer and the interview location were informed by the specific needs of the participant and consideration of their personal circumstances (eg, age, gender and religious beliefs). Initially, interviews were conducted in research pairs (eg, two research team members) to facilitate a standardised approach. Interviews were audio-recorded (except for two where consent for audio-recording was not provided), transcribed verbatim upon completion and on average, lasted $50 \mathrm{~min}$. Four of the interviews with participants of CALD backgrounds were conducted with a bilingual interpreter upon the request of the participant. Interpreters were respected and trusted by each participant and had well-established connections with the participant's cultural values and beliefs. To ensure interviewer consistency, verbal and written interview debriefs were initiated, and feedback from the research team was provided to the interviewers throughout the data collection process. Table 2 summarises the characteristics of study participants.

\section{Data analysis}

Transcribed interviews were analysed concurrently using an iterative thematic approach via the constant comparison method (Glaser, 1965). Three researchers read and re-read the transcripts to familiarise themselves with the data, and used the electronic qualitative data analysis package QSR NVIVO 9(C) (QSR International Pty Ltd., 2010) to code the data into themes and sub-themes in accordance with thematic analysis. Using this approach, data collection and analysis were based on an integrated rather than a linear process, with each interview informing the collection of subsequent interview data.

After initial coding, interviews were further explored to develop sub-themes, leading to their further refinement. Annotated cards were also used during this process to record how the themes were derived and what they represented. All participants were assigned one or more codes in order to ensure the auditability of the analysis. For example, $\mathrm{C}$ represented consumer only, CA carer only, CC consumer and carer, IND Aboriginal and Torres Strait Islander (Indigenous person), CALD culturally and linguistically diverse person and $\mathrm{CH}$

Table 1 Interview questions/prompts relevant to $\mathrm{CHOs}$

Tell me about your journey since you were first told about your condition(s)?

How has your condition(s) impacted on your life?

Tell me about some of the things you do to manage your condition(s)?

Are you a member of a $\mathrm{CHO}$ and why/why not?

How is the CHO helping you manage your condition?

$\mathrm{CHO}=$ consumer health organization. 
Table 2 Characteristics of the study sample

\begin{tabular}{|c|c|c|c|}
\hline \multicolumn{2}{|c|}{ Participant characteristics } & \multirow[t]{2}{*}{$(n=97)$} & \multirow[t]{2}{*}{$(\%)$} \\
\hline Age & Mean $=57.2$ years, $S D=13.03$ & & \\
\hline \multirow[t]{2}{*}{ Gender } & Male & 32 & $33 \%$ \\
\hline & Female & 65 & $67 \%$ \\
\hline \multirow[t]{2}{*}{ Location } & Rural/remote (eg, Mt Isa, Queensland) & 36 & $37 \%$ \\
\hline & Urban/metropolitan (eg, Perth, Western Australia) & 61 & $63 \%$ \\
\hline \multirow[t]{3}{*}{ Carer or consumer } & Consumer only (C) & 69 & $7 \%$ \\
\hline & Carer only (CA) & 12 & $1 \%$ \\
\hline & Carer/consumer (CC) & 16 & $17 \%$ \\
\hline \multirow[t]{3}{*}{ Cultural background } & Aboriginal and Torres Strait Islander & 23 & $24 \%$ \\
\hline & $\begin{array}{l}\text { CALD, for example, Egyptian, Lebanese, Japanese, German, Bosnian, } \\
\text { Burmese, Italian, Samoan }\end{array}$ & 19 & $20 \%$ \\
\hline & Caucasian & 55 & $57 \%$ \\
\hline \multirow[t]{2}{*}{ Chronic illness(s) } & One chronic illness only & 10 & $12 \%$ \\
\hline & Two or more illnesses & 75 & $88 . \%$ \\
\hline \multirow[t]{9}{*}{ Type of illness(s) } & Cancer & 15 & $18 \%$ \\
\hline & Diabetes & 37 & $44 \%$ \\
\hline & Cardiovascular & 68 & $80 \%$ \\
\hline & Renal & 7 & $8 \%$ \\
\hline & Mental illness & 24 & $28 \%$ \\
\hline & Musculoskeletal & 20 & $24 \%$ \\
\hline & Neurological & 18 & $21 \%$ \\
\hline & Respiratory & 27 & $32 \%$ \\
\hline & $\begin{array}{l}\text { Other (eg, quadriplegic, hypothyroidism, insomnia, Meniere's disease, } \\
\text { macular degeneration, polio, reflux, polycystic ovary syndrome, chronic } \\
\text { bladder infection, chronic acne, Hashimoto's disorder) }\end{array}$ & 57 & $67 \%$ \\
\hline
\end{tabular}

CALD = culturally and linguistically diverse.

represented a person who was a healthcare professional but who simultaneously was either a carer, someone who experienced a chronic condition, or both. Authenticity of the analysis was ensured with a member of the research team randomly selecting samples of data for review of coding. The data analysis process was discussed and reviewed by the entire research team whose members had different levels of research expertise (eg, senior researchers to investigators). Data saturation was established for the interviews when the participants' experiences and perspectives became recurring.

\section{Results}

Three inter-related themes were identified that represented the benefits of involvement and participation in CHOs from the perspectives of consumers and carers (Figure 1): knowledge and information, connection and support and experiential learning. Limited access pathways emerged as an entry barrier, which inhibited a person's entry into a CHO. Finally, user beliefs and experiences emerged as a progress barrier, which inhibited the continued involvement in a $\mathrm{CHO}$ once a person had participated in $\mathrm{CHO}$ programmes.

\section{Benefits}

\section{Knowledge and information}

One of the most fundamental reasons for joining a $\mathrm{CHO}$ was to obtain knowledge and information, which was a core component of self-management. Participating in programmes offered by such organisations provided invaluable knowledge and information about a person's condition(s), including symptoms, treatment options, practical solutions and coping strategies, all of which are essential for self-management. For example, one participant with osteoarthritis discussed keeping up to date on information about new developments in treatment:

....it keeps you abreast of modern developments...You know new drugs, new research

[C_1001] 


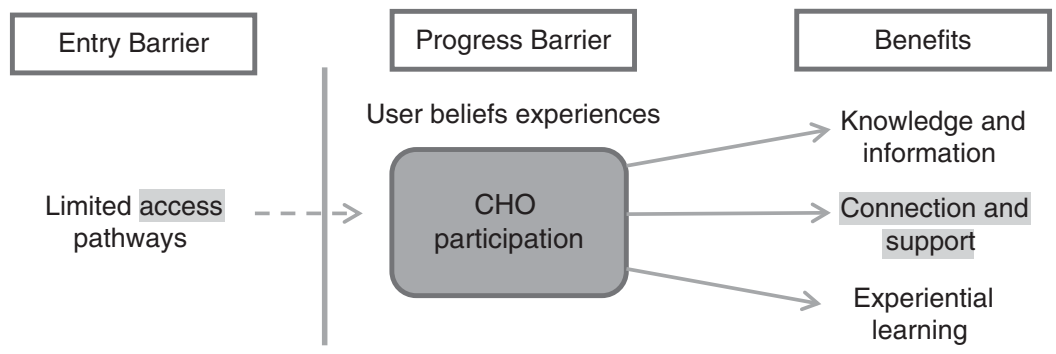

Figure 1 Barriers and benefits of consumer health organisation participation

An Aboriginal and Torres Strait Islander person with multiple conditions indicated that participation in $\mathrm{CHO}$ programmes equipped her with the necessary resources to self-manage her illness:

...that's what this programme does for you,... [conducted by the $\mathrm{CHO}$ ] it gives you the education so you can self-manage, which is brilliant

$$
\text { [C(IND)_1164] }
$$

$\mathrm{CHO}$ programmes, through knowledge and information, instilled confidence in members' selfmanagement practices and ability to cope with their conditions. Quite often, CHOs would have guest speakers to present information to members on a particular chronic condition. A healthcare professional who was an unpaid carer of a young child with asthma discussed the value of information and education provided by $\mathrm{CHOs}$, and encouraged their use by other health consumers:

I actually think they're [CHOs] excellent. I mean I've used them a lot in my work. I do, I think they're an excellent, excellent resource

$$
\text { [CC(HP)_1049] }
$$

Carers seemed particularly appreciative of the knowledge and information they obtained through $\mathrm{CHO}$ programmes. Carers were able to better understand the health conditions which the person they cared for experienced. A consumer/carer of an adult with a mental illness mentioned:

Quite a revelation at first and we got into the swing of it and learnt about it. we've got an understanding of his condition even though he hasn't

$$
\text { [CC_1016] }
$$

\section{Connection and support}

Emotional, practical and financial support and connection were other important reasons for joining CHOs. Emotional support was particularly important for participants who did not have an extended support network. CHOs provided emotional support and connection by providing advice, understanding and encouragement. One participant claimed to have successfully quit smoking as the result of the emotional support and encouragement she received from a lung support group. She further added that the support group gave her hope and made her realise that she could live a long normal life with her condition. When asked what her main reason for joining a $\mathrm{CHO}$ was, an Aboriginal and Torres Strait Islander woman with multiple health conditions replied:

They were non-judgemental. I wasn't just another mental case or a hypochondriac. They had understanding and compassion and they had time

$$
\text { [C(IND)_1095] }
$$

When asked to comment on the emotional support she received from the $\mathrm{CHO}$ which she attended, a participant from a CALD background with comorbidity passionately responded:

They are like family to me now

$$
\text { [C(CALD)_1134] }
$$

Mixing with others, comfort from knowing that they were not alone, and opportunities to participate in social outings were positively discussed. In relation to practical support, some CHOs assisted members with personal care and household duties, with an elderly female with multiple conditions explaining:

... they [carer from a $\mathrm{CHO}$ ] come around and mowed my lawn for ten dollars...for anything 
that goes wrong in a home, they'll [CHO] come around and fix it up and it doesn't cost much

[C(IND)_1097]

Another participant from a CALD background added:

They send this lady, she come two hours three times a week. I can't wash myself, she wash me, she wash the dishes and she cook once a week

[C(CALD)_1134]

Another participant with diabetes relied upon the support of $\mathrm{CHO}$ to purchase her medication:

....all my pump consumables and things like that I go through [name of $\mathrm{CHO}$ ]... They're brilliant on their delivery, straight to my door so I don't have to think about it...

[C_1121]

CHOs also offered support to the carer, sometimes assisting them to access respite from their role, with a carer admitting:

I don't know how much my husband actually was aware of them [CHO] being there, but for me, it boosted me, it was just what I needed

[CA_1149]

Finally, CHOs also provided participants with financial support. For example, a carer for her quadriplegic partner discussed how a $\mathrm{CHO}$ and a private donor provided financial support with the purchase of a highly sophisticated massage chair for her partner, which would otherwise have been unaffordable:

[name of CHO] helped. There was actually a private donor, donating so much [name of $\mathrm{CHO}$ came up with a couple of hundred I think

[CA_1071]

\section{Experiential learning}

For many participants, CHOs created opportunities for experiential learning with others who had similar chronic conditions. Participants described instances where they benefited from other's experiences and learnt about available treatment options. For example, a person who contemplated having surgery suggested:

I met one lady at the class [offered by $\mathrm{CHO}$ who'd had it, the operation ... you're really good when you first have it done and then within five years you just, you're back to where you were

Participating in $\mathrm{CHOs}$ also provided members an opportunity to openly discuss their experiences with primary healthcare services and professionals with each other:

The other thing we do again with.... [name of $\mathrm{CHO}$ ] we say you know I have been to see so and so and they were very good

$$
\text { [C_1008] }
$$

Others found comfort in discussing matters unrelated to their illness, which provided an escape from the realities of everyday life. Furthermore, the ability to share confidential experiences and personal feelings eased the pressure on other relationships (eg, with a carer, spouse and child).

Furthermore, the experiential knowledge obtained through interaction with other consumers made members 'experts in their illness', enabling them to engage in more constructive discussions with their healthcare providers:

...I think coming to the ...[CHO programme's name] it gives us [participant referring to ability], to be able to understand and to be able to talk to the doctors, because we do understand what our health problems are

[C(IND)_1163]

\section{Entry barrier}

\section{Limited access pathways}

An important barrier that inhibited participants' entry into CHOs was the underdeveloped pathways between GPs and such organisations. Access pathways between other medical (eg, neurologist, physiotherapist) and healthcare providers (eg, diabetes educator and naturopath) appeared to be more developed than with GPs, with some participants claiming to join a $\mathrm{CHO}$ as a result of direct encouragement from such providers. 
Many participants believed to have received minimal and sometimes no encouragement from their primary physician to seek and join a CHO. When asked about their first encounter and referral processes to $\mathrm{CHOs,} \mathrm{some} \mathrm{participants} \mathrm{relied} \mathrm{on}$ personal effort and utilisation of their own networks (eg, friends or family members):

I then started to do some research myself and I went to the...[name of $\mathrm{CHO}]$

[C_1052]

When discussing her first encounter with a $\mathrm{CHO}$, a young mother with Graves' disease said:

I was just looking at those [advertisements] randomly and I just found the notice there the other day [workshop conducted by a $\mathrm{CHO}$. There is a talk going on in a couple of weeks' time

$$
\text { [C(CALD)_1152] }
$$

Another participant who experienced chronic back pain as a result of a workplace injury discussed her need to start a support group with a friend to cope with feelings of isolation and loneliness. Discussing her journey in initiating such a support group, she claimed to have received minimal support from primary healthcare professionals (mainly the GP):

I actually wrote to all the doctors at our local medical centre just telling them about our group and asking them to refer patients... we asked if we could just put up a flyer on their notice board as well just telling people about the group. And they just haven't done that

[C_1080]

Another participant who developed lung disease as a result of complications from pneumonia described a similar experience:

My GP has been excellent... He's open minded to the use of natural remedies and even encourages them for use. The one thing I have found unusual with him is that... I have been trying to get him to support my lung support group but he thinks I am the only patient he has with lung disease. I find this difficult to believe

[C(IND)_1141]
When this participant was asked what he would have preferred to have happened, he replied:

I think the GPs and all that... should be aware of all the carer groups and all the support groups

[CC_1016]

When asked which health professional was best placed to provide information about $\mathrm{CHOs,}$ another participant corroborated:

Your general doctor...Because they're the ones that most people go to first

[C_1060]

\section{Progress barrier}

\section{User beliefs and experiences}

Although limited access pathways emerged as an entry barrier, user experience inhibited the continued involvement in a $\mathrm{CHO}$ once a person had participated in their programmes. Many of these participants previously partook in various programmes but ceased their involvement mainly because of their personal beliefs about their own health condition(s), support needs and also their experiences of CHOs. There was a sense of belief among some participants that $\mathrm{CHOs}$ could not provide any further assistance with their conditions. These participants claimed to have become 'experts' in their health, as a result of learning to live with and self-manage their conditions for an extended period of time. A participant with diabetes mentioned:

... when you've been a diabetic for sixty years, I don't think there's a lot you can learn

[CC_1021]

Another who was born with chronic asthma and depression confirmed:

....because I was diagnosed at only fifteen months of age I've never known anything different than having that condition. I came through

[CC_1166]

Some participants also questioned the suitability of group programmes for them personally. 
For example, a participant with chronic obstructive pulmonary disease and depression, who participated in a $\mathrm{CHO}$ programme, questioned the age group and discussed the difficulty of fitting in:

I got there [CHO workshop], there were eight people and they were that old, I mean they were all in you know one foot in the grave... So I've got that big age gap

$$
\text { [C_1017] }
$$

Others were reluctant to seek social contact through a $\mathrm{CHO}$ because contact with others who experienced the same or similar condition(s) became distressing. Several participants even claimed to have become depressed as a result of talking about their conditions and seeing others who developed complications because of participation in $\mathrm{CHO}$ programmes:

I didn't want to sit there and listen to everybody else complain all the time 'cause it's depressing

[C(CH)_1127]

I joined a.... [self-help group] on the computer and I found that in the end, I felt very depressed by it, I thought oh these poor people

[C_1014]

Participation in CHOs also provoked feelings of 'incapability' and 'helplessness' in some participants:

I don't class myself as an invalid, so going to places like that... I found it more or less for me, not for other people, for me, like a waste of time

$$
\text { [CC(CALD)_1038] }
$$

One of the fundamental reasons for not joining or ceasing to be a proactive member of a $\mathrm{CHO}$ were the participant's personal beliefs about their desire to discuss their health conditions. Some participants perceived discussing their health conditions as a sign of weakness, with one participant claiming:

I don't want to be whinging about my situation, I don't want to be talking about my depression

[C(CALD)_1069]

\section{Discussion}

Managing chronic illness can be 'hard work' (Corbin and Strauss, 1985), characterised by obtaining knowledge and information, organising treatment, changing lifestyle and coping with symptoms. Although the formal primary healthcare system helps support people, most of this 'hard work' rests on people's personal efforts and coping strategies (May et al., 2009). This calls for a greater emphasis on informal healthcare services to provide people the necessary resources to effectively self-manage their chronic conditions. The findings of this study reinforce the notion that CHOs have a complementary role and make a valuable contribution in alleviating the hard work associated with self-managing chronic conditions. Our findings suggest that for most participants, accessing CHOs provide knowledge and information about their condition(s), various treatment options, support and encouragement for healthy lifestyle changes, and a sense of connection and experiential learning that they find empowering. For most participants we interviewed, the resources offered by $\mathrm{CHOs}$ were fundamental in enhancing the capacity of people to effectively engage in selfmanagement of their chronic health conditions. Given that the management of chronic conditions can be characterised by 'hard work', our findings are consistent with existing literature (Coppa and Boyle, 2003; Nijsten et al., 2005; Sav et al., 2012), which demonstrates the fundamental value of $\mathrm{CHOs}$ in alleviating some of this work for consumers and their carers.

The important and complementary role of CHOs in chronic illness management underscores the need for better integration of these organisations into the primary healthcare system. Greater integration of CHOs is also necessary in the context of current health system constraints (Boyle et al., 2009). Primary healthcare systems may not provide consumers with adequate access to the non-clinical and psychosocial aspects of care (eg, experiential knowledge) that they need in order to effectively self-manage their ongoing health conditions (Boyle et al., 2009). Furthermore, as a result of short consultation times, GPs can be restricted in providing the amount of information or the necessary support and training required for effective self-management (Sav et al., 2012). Our findings indicate that $\mathrm{CHO}$ can provide users with 
experiential knowledge, a sense of connection and collaboration with other people, emotional support and encouragement, information sharing and practical assistance, all of which may be difficult to obtain within the formal primary healthcare system.

Despite their potential, limited access pathways inhibited some peoples' entry and participation with $\mathrm{CHOs,}$ thereby restricting their ability to utilise this largely untapped resource ( $\mathrm{Sav}$ et al., 2012). The lack of access pathways between CHOs and GPs also seem to be a key determinant of a lack of $\mathrm{CHO}$ usage among consumers within the literature (Young et al., 2010). Although the reasons for poor referral are complex, research indicates the overriding factors are the physician's concern about the misinformation and the potential for such organisations to cause psychological harm (Steginga et al., 2007). Based on the comments of some participants in our study, interaction with others who experience the same or similar health conditions can indeed be associated with psychological harm (eg, depression). However, because of the scarcity of research in this area, it is difficult to exactly know if, how and under what circumstances, CHOs can have negative effects on people's health.

Despite the potential value of CHOs in providing psychosocial aspects of care for effective selfmanagement, it is important to recognise that there is no one-size fits all solution. Our findings suggest that some participants may not benefit from involvement in CHOs. As a result of becoming 'experts' in their health, some participants may feel that there is little that CHOs can offer. Some people may even find social contact with others depressing while others can enjoy the company and opportunities for engagement. This underscores the need for consumer-directed holistic care that is responsive to each person's unique circumstances and preferences (Sav et al., 2013). Although CHOs are an important avenue for obtaining assistance and resources, multiple strategies, services and avenues of support are needed to empower people to become more resilient and engage in effective self-management behaviours (eg, learning about treatments, coping with difficulties, adjusting lifestyle, gaining support, etc.; Coppa and Boyle, 2003).

Our findings corroborate the beneficial impact of such organisations for the majority of people with chronic conditions and their carers.
Furthermore, there is a need for further integration into the healthcare system to increase the reliable delivery and accessibility of CHOs. Such integration systems are needed to ensure that people who would benefit from accessing these organisations can do so (Boyle et al., 2003). The National Diabetes Services Scheme (NDSS) is one example of an Australian government initiative that has been successfully integrated into the primary healthcare system. This initiative is administered through Diabetes Australia, a $\mathrm{CHO}$ that provides assistance, information and support for people with diabetes (Diabetes Australia, 2013). Most importantly, however, it provides subsidised products (eg, insulin) to people experiencing diabetes, which can minimise the widely reported financial burden of treatment (Sav et al., 2013). Users can purchase subsidised products through NDSS Access Points, usually located in community pharmacies and primary healthcare clinics. The availability of NDSS in community pharmacies not only enables people to obtain subsidised products, but also allows them to more readily access information and advice on diabetes.

In contrast, while $\mathrm{CHOs}$ for other common chronic conditions, such as cardiovascular disease, asthma and cancer exist, a NDSS type of initiative is not available for these disease states. Until such initiatives exist for other chronic conditions, GPs must make a personal effort to discuss $\mathrm{CHO}$ access and provide information on the range of $\mathrm{CHOs,}$ thereby creating pathways for their patients into longer-term supportive communities. A resource kit, which provides information on the range of CHOs available for chronic condition(s), such as one compiled for community pharmacists (Campbell et al., 2013), may be a valuable resource. Because GPs are viewed as being highly trustworthy (Kreuter et al., 2000), their endorsement of CHOs is likely to increase the likelihood that consumers will seek support from such organisations. Finally, referral from other primary healthcare professionals should be explored further to provide GPs an understanding of successful referral processes.

Strategies to increase referral between CHOs and GPs do not only fall on the shoulders of GPs but also on CHOs themselves. CHOs must make proactive efforts to collaborate with GPs and simplify the process for GPs to refer their patients to such organisations for effective self-management (Boyle et al., 2003). At a most basic level, CHOs 
can disseminate information about their complementary role in self-management via mail-outs, brochures, face-to-face meetings and invitations for GPs to participate in $\mathrm{CHO}$ programmes. Additionally, CHOs should also reach out to people who have not been able or willing to access them to self-manage their conditions.

\section{Limitations and strengths of this study}

Limitations of this study include the use of qualitative cross-sectional data collection at one point in time, thereby limiting our ability to explain how a person's use of $\mathrm{CHO}$ changes over time. Furthermore, the results are based on selfreported data, risking the possibility that some participants' gave a socially desirable response (eg, benefits of CHO usage). Although interviews were conducted by different researchers, we are confident that any risk of interviewer bias was minimised with the use of a standardised interview guide and by sharing debriefs with the research team for each interview. Furthermore, the completion of the initial interviews by pairs minimised the risk of interviewer bias. Although a nonrandom purposive (snowball) sampling strategy to locate participants may reduce the generalisability of our findings, this particular sampling method enabled us to recruit participants from minority groups, from affluent and disadvantaged communities and with a range of chronic conditions. Other entry level barriers might have emerged, including misperceptions about what $\mathrm{CHOs}$ are able to offer or how they operate, if our sample consisted of more participants who had no contact with CHOs. Indeed, the strength of our study, in addition to the number of interviews that allowed saturation of themes to be reached, was the ability to obtain a wide range of perspectives from groups of people that are often not included in primary healthcare research. Finally, although our study had representation from CALD backgrounds, most of these participants were of Caucasian backgrounds (eg, German, Bosnian, Italian, etc.). Future research should focus on a broader range of culturally diverse participants to help understand the role of culture in CHO experiences. Despite these limitations, this study provides an inclusive understanding of the benefits of CHOs and the barriers that limit involvement in such organisations, from the perspective of first-hand users (eg, people with chronic conditions and their carers).

\section{Conclusion}

Overall, this study confirms that CHOs are a valuable resource in alleviating the 'work of being a patient' for some people with chronic conditions and their unpaid carers. The rise of chronic conditions worldwide and the resulting pressures on primary healthcare services are likely to place an even greater emphasis on the role of CHOs in helping people to self-manage their conditions. However, the optimal access and utilisation of CHOs are obscured by the barriers that inhibit user involvement. Such barriers need to be systematically addressed to ensure that the full potential of CHOs is achieved.

\section{Acknowledgements}

The authors would like to thank the participants who participated in this study and the organisations that assisted with recruitment. They would also like to thank Beth Hunter, Claire Campbell, and Ciara McLennan for their assistance with data collection.

\section{Funding Acknowledgement}

This project is funded by the Australian Government Department of Health as part of the Fifth Community Pharmacy Agreement Research and Development Program managed by The Pharmacy Guild of Australia. The financial assistance provided must not be taken as endorsement of the contents of this report.

\section{Conflicts of Interest}

The authors confirm that there is no conflict of interest.

\section{References}

Allsop, J., Jones, K. and Baggott, R. 2004: Health consumer groups in the UK: a new social movement? Sociology of Health and Illness 26, 737-56.

Blenkinsopp, A., Holmes, J., Mitra, G. and Pringle, M. 2009: Joing up self-care: evaluation of a PCT-wide programme of support for self-care. Primary Health Care Research \& Development 10, 245-54. 
Boyle, F.M., Donald, M., Dean, J.H., Conrad, S. and Mutch, A.J. 2007: Mental health promotion and non-profit health organisations. Health and Social Care in the Community $15,553-60$.

Boyle, F.M., Mutch, A.J., Dean, J.H., Dick, M.L. and Del Mar, C.B. 2009: Consumer health organisations for people with diabetes and arthritis: who contacts them and why? Health and Social Care in the Community 17, 628-35.

Boyle, F.M., Mutch, A.J., Dean, J.H., Dick, M.L. and Del Mar, C.B. 2011: Increasing access to consumer health organisations among patients with chronic disease - a randomised trial of a print-based intervention. Primary Health Care Research \& Development 12, 245-54.

Boyle, F.M., Posner, T.N., Del Mar, C.B., Mclean, J. and Bush, R.A. 2003: Self-help organisations: a qualitative study of successful collaboration with general practice. Australian Journal of Primary Health 9, 75-79.

Campbell, C., Kelly, F., Sav, A., McMillan, S.S. and Wheeler, A.J. 2013: Could pharmacies be the missing link between Consumer Health Organisations and health consumers? Pharmacy News [Online]. Retrieved 17 June 2013 from http://www. pharmacynews.com.au/news/latest-news/pharmacies-missinglink-between-consumers-and-cho

Coppa, K. and Boyle, F.M. 2003: The role of self-help groups in chronic illness management: a qualitative study. Australian Journal of Primary Health 9, 68-74.

Corbin, J. and Strauss, A. 1985: Managing chronic illness at home: three lines of work. Qualitative Sociology 8, 224-47.

Diabetes Australia. 2013: The National Diabetes Services Scheme (NDSS). Retrieved 11 January 2013 from http:// www.ndss.com.au/

Ellins, J. and Coulter, A. 2005: How engaged are people in their health care? Findings of a national telephone survey. Oxford: Picker Institute Europe. Retrieved 23 July 2013 from http://www.health.org.uk/public/cms/75/76/313/3834/How\%20 engaged $\% 20$ are $\% 20$ people $\% 20$ in $\% 20$ their $\% 20$ healthcare $\% 20$ full \%20report.pdf?realName=vqk1xh.pdf

Glaser, B.G. 1965: The constant comparative method of qualitative analysis. Social Problems 12, 436-45.

Hoffmann, T. and O'shea, J. 2012: An evaluation of the effectiveness of a brief self-management educational expo provided by a consumer health organisation for people with type 2 diabetes. Therapeutic Patient Education 4, 41-46.

Jones, K., Baggott, R. and Allsop, J. 2004: Influencing the national policy process: the role of health consumer groups. Health Expectations 7, 18-28.

Katz, A.H. and Bender, E.I. 1976: Self-help groups in western society: history and prospects. Journal of Applied Behavioral Science 12, 265-82.

Kreuter, M.W., Chheda, S.G. and Bull, F.C. 2000: How does physician advice influence patient behavior? evidence for a priming effect. Archives of Family Medicine 9, 426-33.

Kyrouz, E., Humphreys, K. and Loomis, C. 2002: A review of research on the effectiveness of self-help mutual aid groups.
In White, B.J. and Madara, E.J., editors, The self-help support group. Cedar Knolls: American Self-Help Clearinghouse, 71-85.

Laudet, A.B. 2000: Substance abuse treatment providers' referral to self-help: review and future empirical directions. International Journal of Self Help Self Care 1, 213-25.

Lorig, K. and Holman, H. 2003: Self-management education: history, definition, outcomes, and mechanisms. Annals of Behavioral Medicine 26, 1-7.

May, C., Montori, V.M. and Mair, F.S. 2009: We need minimally disruptive medicine. British Medical Journal 339, 485-87.

McMillan, S.S., Wheeler, A.J., Sav, A., King, M.A., Whitty, J.A., Kendall, E. and Kelly, F. 2012: Community pharmacy in Australia: a health hub destination of the future. Research in Social and Administrative Pharmacy, 9, 863-75.

Mcnamara, B. and Rosenwax, L. 2010: Which carers of family members at the end of life need more support from health services and why? Social Science \& Medicine 70, 1035-41.

Neuman, W.L. 2010. Social Resarch Methods: Qualitative and Quantitative Approaches. Boston: Pearson Education.

Nijsten, T., Rolstad, T., Feldman, S.R. and Stern, R.S. 2005: Members of the national psoriasis foundation: more extensive disease and better informed about treatment options. Archives of Dermatology 141, 19-26.

Oliffe, J.L., Bottorff, J.L., Mckenzie, M.M., Hislop, T.G., Gerbrandt, J.S. and Oglov, V. 2011: Prostate cancer support groups, health literacy and consumerism: are communitybased volunteers re-defining older men's health? Health 15 , 555-70.

QSR International Pty Ltd. 2010: NVIVO 9 Referencing. Doncaster Victoria, Australia: Author.

Salzer, M.S., Rappaport, J. and Segre, L. 2001: Mental health professionals' support of self-help groups. Journal of Community \& Applied Social Psychology 11, 1-10.

Sav, A., King, M.A., Whitty, J.A., Kendall, E., Mcmillan, S.S., Kelly, F., Beth, H. and Wheeler, A.J. 2013: Burden of treatment for chronic illness: a concept analysis and review of the literature. Health Expectations, 31 January 2013, DOI: 10.1111/hex.12046.

Sav, A., Mcmillan, S.S., Kelly, F., Kendall, E., Whitty, J.A., King, M.A. and Wheeler, A.J. 2012: Treatment burden among people with chronic illness: what are consumer health organizations saying? Chronic Illness 9, 220-32.

Steginga, S.K., Smith, D.P., Pinnock, C., Metcalfe, R., Gardiner, R.A. and Dunn, J. 2007: Clinicians' attitudes to prostate cancer peer-support groups. British Journal of Urology International 99, 68-71.

World Health Organization. 2011: Noncommunicable diseases country profiles 2011. Geneva, Switzerland: World Health Organization.

Young, C.E., Mutch, A.J., Boyle, F.M. and Dean, J.H. 2010: Investigating referral pathways from primary care to consumer health organisations. Australian Journal of Primary Health 16, 260-67. 